\title{
OS SENTIDOS CONTEMPORÂNEOS DAS COISAS DO PASSADO: REFLEXÕES A PARTIR DA AMAZÔNIA ${ }^{1}$
}

The Contemporary Senses of the Things of the Past: reflections from Amazon

\section{Marcia Bezerra ${ }^{2}$}

\section{RESUMO}

O texto trata da relação entre as comunidades locais na Amazônia e o patrimônio arqueológico, considerando a percepção tátil como elemento importante no reconhecimento e na apropriação das coisas do passado. Com base no mapeamento desses casos em distintas localidades, proponho a reflexão sobre a potencialidade das pesquisas acerca dos sentidos que permeiam tais relações e a sua contribuição para a legitimação dos discursos nativos sobre o passado e para a gestão dos bens arqueológicos. $\mathrm{O}$ artigo apresenta as primeiras considerações de um estudo recém-iniciado e voltado para o entendimento dos usos contemporâneos das coisas do passado.

Palavras-chave: arqueologia pública, sentidos, Amazônia

\begin{abstract}
The paper considers the relationships between the local communities and the archaeological heritage, in Amazon, regarding the haptic perception as an important element to the recognition and appropriation of things of the past. Based on the survey of these cases in different places, I propose a reflection on the promising researches concerning the senses that pervade these relationships and their contribution to legitimate native discourses about the past and to enhance archaeological resource management. The paper presents the first thoughts of a recently initiated study towards the understanding of contemporary uses of things of the past.
\end{abstract}

Keywords: public archaeology, senses, Amazon

\section{RESUMEN}

El texto trata de la relación entre las comunidades locales en la Amazonia y el patrimonio arqueológico, teniendo en cuenta la percepción táctil como un elemento importante en el reconocimiento y la apropiación de las cosas pasadas. En base a la cartografía de estos casos en diferentes lugares, propongo una reflexión sobre el potencial de las investigaciones sobre los sentimientos que subyacen en este tipo de relaciones y su contribución a la legitimación de los discursos indígenas sobre el pasado y para el tratamiento de los restos arqueológicos. El

\footnotetext{
${ }^{1}$ Uma versão desse texto foi apresentada no 7th World Archaeological Congress, na Jordânia, em Janeiro de 2013. A pesquisa é resultante de projetos de Arqueologia Pública, na Ilha do Marajó, e de Educação Patrimonial, em várias localidades na Amazônia.

${ }^{2}$ Doutora em Arqueologia/USP Iphan/UFPA/CNPq, e-mail: marciabezerrac14@gmail.com
} 
artículo presenta las primeras consideraciones de un estudio recientemente iniciada y dirigida a la comprensión de los usos contemporáneos de las cosas del pasado.

Palabras clave: arqueología pública, los sentidos, Amazonia

\section{Introdução}

As reflexões oriundas das pesquisas sobre as relações de distintas comunidades locais com o patrimônio arqueológico têm tido impacto direto no reconhecimento das narrativas nativas sobre o passado e na gestão desses bens. No entanto, apesar do expressivo volume de estudos sobre o tema (EBBIT, 2010; FERREIRA, FERREIRA, ROTMAN, 2011; FUNARI，BEZERRA，2012; GNECCO，AYALA，2010; HERRERA，LANE，2006; LONDOÑO, 2003; MIRE, 2007; NAJJAR, 2001; OKAMURA, MATSUDA, 2011; PYBURN, 2009; SILVA, 2002), há pontos importantes que ainda merecem ser examinados. Dentre eles, enfatizo, neste artigo, o imbricamento sensorial (CLASSEN, 2005; HODDER, 2012; THOMAS, 1991;) das pessoas com as coisas do passado - um tema pouco contemplado, particularmente pelos arqueólogos.

Um dos aspectos não muito explorados, e que configura quase uma interdição, é o uso contemporâneo dos bens arqueológicos. Refiro-me, aqui, aos artefatos e aos sítios apropriados como materializações (BELL, GEISMAR, 2009) destacadas da categoria "patrimônio", mas enganchadas nas paisagens cotidianas dessas comunidades. Cito como exemplos a prática do futebol em uma área das ruínas do sítio de Sacsayhuaman, em Cuzco, Peru, narrada por um arqueólogo, ele mesmo participante do jogo com moradores locais (STANCHI, 2001); e o uso de machados polidos - do período pré-colonial - como pesos de porta na Amazônia, entre outros.

Tais situações denotam uma riqueza de elementos fundamentais para o entendimento das percepções sobre a cultura material. Pensar sobre esses casos contribui para a consolidação do campo da arqueologia sensorial e amplia o escopo de discussões para as sensibilidades contemporâneas sobre as coisas $^{3}$ do passado.

É nessa perspectiva que venho, nos últimos anos, mapeando os distintos usos contemporâneos das coisas arqueológicas, o que me levou a propor, em trabalhos anteriores

\footnotetext{
${ }^{3}$ Tal como já discutido em trabalhos anteriores (ver BEZERRA, 2012), adoto o termo "coisa" a partir de Bell e Geismar (2009). Segundo os autores, o termo "coisa" desconstrói a habitual naturalização da cultura material como uma categoria que "obscurece as distinções locais". Compreendo que essa noção permite, então, pensar sobre essas relações para além da categoria "patrimônio" inventada pelo Estado.
} 
(BEZERRA, 2012), a consideração de tais práticas como resultantes de formas particulares de fruição com o passado. É sempre importante ressaltar que não estou sustentando a ideia de que os atos de vandalismos e/ou saques aos sítios arqueológicos são legítimos, no entanto, sugiro a observação das apropriações locais do que denominamos por "patrimônio arqueológico", a partir do que Castañeda (2008: 40) conceitua como "instalação etnográfica" - um lugar onde a confluência de distintas visões de mundo e a subversão das relações verticalizadas entre pesquisadores e comunidades moradoras do entorno de sítios arqueológicos instauram um locus para a construção de outras interpretações sobre as coisas do passado.

Tendo por base a proposição de Castañeda e a premissa de que as apropriações contemporâneas da cultura material constituem uma forma singular de fruição com o passado (BEZERRA, 2012), discuto a importância de se considerar o domínio sensorial dessas percepções, particularmente a sua natureza tátil (PYE, 2007). Assim, a partir de estudos de caso na Amazônia, proponho a reflexão sobre: 1) a desvalorização do potencial das pesquisas sobre os sentidos na compreensão das práticas culturais; 2) os paradoxos do discurso da Arqueologia contemporânea; e 3) a instrumentalização do patrimônio no campo da preservação. Os exemplos aqui tratados mostram que o deslocamento do olhar sobre o patrimônio - da norma da preservação para a forma de fruição - e da própria categoria "patrimônio" para "coisas" contribui para o avanço dos debates sobre a simetria nas relações entre arqueólogos e comunidades locais.

\section{O estudo dos sentidos}

O estudo dos sistemas sensoriais como caminho para entender a cultura não é novidade no campo da Antropologia. Pesquisadores como Classen (1997, 2005), Gosden, Edwards e Phillips (2006) têm dado intrigantes e criativas interpretações sobre os "objetos sensíveis" e seu papel em distintas ordens sensoriais.

No contexto amazônico, a ordem do sensível foi, exaustivamente, discutida por Viveiros de Castro (1996) ao tratar do perspectivismo ameríndio. Nessa perspectiva, o mundo é constituído por distintas categorias de seres - humanos e não-humanos. Cada uma vê a si mesma como humana e as demais como não-humanas. Nas cosmologias ameríndias geradoras dessas elaborações, no início, todos os seres eram humanos e, posteriormente, por "atos tecnológicos" (VAN VELTHEM, 2003:90), foram se diferenciando: tornaram-se humanos, 
plantas, animais e artefatos. Contudo, se para Viveiros de Castro, os objetos têm lugar secundário nessa dinâmica, para Santos-Granero (2009), as coisas são centrais para a vida humana e a reprodução, têm uma "vida oculta". A fecunda produção de conhecimentos sobre o tema na Amazônia levou Santos-Granero a propor a existência de uma epistemologia ameríndia da cultura material ${ }^{4}$.

No campo da Arqueologia, as contribuições que contemplam a dimensão do sensível, na Amazônia, ainda são incipientes. Os estudos conduzidos por Barreto (2008), Gomes (2012) e Schaan (2004), entre outros, resultaram em interpretações sobre o registro arqueológico pré-colonial, que de forma direta, ou indireta, se beneficiaram das discussões sobre a ordem do sensível. As reflexões propostas por Machado (2012) no âmbito das relações entre pessoas e plantas na Ilha Caviana também contribuem para as discussões sobre o domínio sensível das paisagens para as populações ribeirinhas. Para a discussão aqui apresentada, dou destaque ao trabalho atualmente desenvolvido por Cabral (2011) com indígenas Wayãpi, no Amapá, e que preconiza certa "arqueologia do sensível”.

No entanto, as ativas e cotidianas relações que as comunidades locais da região têm com as coisas do passado implicam a necessidade de se pensar sobre a lógica de construção de outras epistemes. Na Amazônia é frequente observar que as casas se assentam sobre os sítios arqueológicos. Urnas funerárias e outros vasilhames servem como armazenadores de água e/ou farinha. Os moradores aproveitam os sítios de terra preta para fazer suas roças. As crianças, por sua vez, brincam com fragmentos de cerâmica, guardam objetos encontrados na beira de rios, igarapés, nas ruas de terra e formam pequenas coleções (RAVAGNANI, 2011). Há ainda registro do uso de cacos de cerâmica como conservadores de umidade em vasos de plantas e até uma garrafa de grés aproveitada como vaso de flores (MORAES, 2012). Mas o que esses exemplos têm a nos dizer?

\footnotetext{
${ }^{4} \mathrm{Em}$ trabalho anterior discuti a perspectiva indígena sobre os objetos etnográficos que compõem os acervos de museus, considerando a dimensão sensível dessas relações (BEZERRA, MACHADO, 2011).
} 


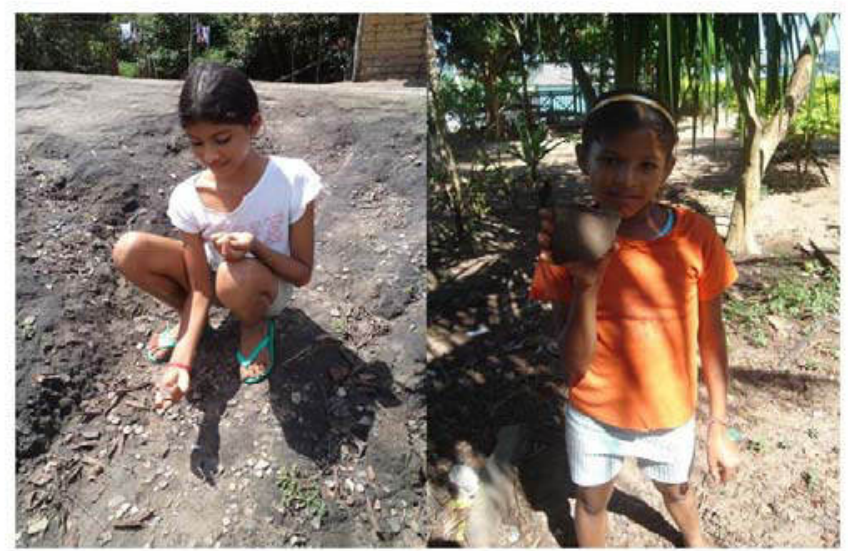

Figura 1: Adriana, de Capanema, e Mariele, de Rurópolis, brincam no quintal de suas casas: dois sítios de terra preta. O primeiro no Rio dos Cacos; o segundo, em Água Azul, na beira da Transamazônica, ambos no estado do Pará. Foto: Marcia Bezerra.

Em recente congresso realizado no Brasil, Zarankín, ao discutir os aspectos sensoriais da prática arqueológica, perguntou: “(...) Qual arqueólogo que nunca pensou nos sentimentos e pensamentos dos grupos que estuda?" (ZARANKIN, 2012). Seguindo a reflexão do colega, questiono: "Qual arqueólogo pensa nos sentimentos e pensamentos dos grupos com os quais lida durante as pesquisas de campo?".

A resposta pode parecer óbvia. Afinal, nas últimas décadas, acompanhamos o significativo aumento de artigos, livros, fóruns e workshops destinados a refletir sobre as inúmeras adjetivações das arqueologias contemporâneas: arqueologia ação (SABLOFF, 2008), colaborativa (MCDAVID, 2002), participativa (PYBURN, 2009), indígena (GNECCO, AYALA, 2010), com descendentes (COLWEL-CHANTHAPHONH, FERGUSON, 2008), comunitária (MARSHALL, 2002) e simétrica (CABRAL, 2011), entre outras. Contudo, se por um lado todas essas "arqueologias" compartilham preocupações sobre a descolonização da prática arqueológica e a simetrização dos discursos nativos e científicos acerca do passado, por outro elas não contemplam a experiência sensorial e o imbricamento das pessoas e das coisas [arqueológicas] (HODDER, 2012; THOMAS, 1991), mas que têm papel fundamental no reconhecimento das múltiplas elaborações sobre o passado.

Os debates sobre a dimensão sensória na Arqueologia não são novos (HAMILAKIS, PLUCIENNIK, TARLOW 2002; HURCOMBE, 2007; JONES, MACGREGOR, 2002; MACGREGOR 1999; OUZMAN, 2001, entre outros) e há uma recente efervescência sobre o tema (DAY, 2013; FAHLANDER, KJELLSTRÖM, 2010; SKEATES, 2010). A coletânea 
editada por Fahlander \& Kjellström, em 2010, revela os desafios da pesquisa sobre o universo perceptual no passado, mas aponta caminhos teóricos e metodológicos para se adensar as interpretações sobre a visão, a audição, o olfato, o paladar e o tato, a partir do registro arqueológico. As pesquisas de MacGregor (1999), Hurcombe (2007) e Ouzman (2001) demonstram, de forma particular, a importância da percepção tátil no estudo de coleções líticas, cerâmicas e até da arte rupestre, respectivamente.

É interessante notar que, não obstante o fato de que a arqueologia lida, inexoravelmente, com a concretude, a dimensão tátil do fazer arqueologia tem atraído poucos pesquisadores, o que vai ao encontro das críticas de Classen (1997, 2005), Edwards, Gosden e Phillips, (2006), Howes (1991) e Stoller (1989) sobre os primeiros estudos no campo da antropologia dos sentidos. Segundo os autores, há uma primazia da visão em relação aos demais sentidos. Como salienta Stoller (op.cit.: 7), é preciso "abrir seus [dos antropólogos] sentidos para os mundos de outros", , de modo que se possa “(...) revelar as distinções e interrelações do significado sensório e prático para uma cultura” (CLASSEN, 1997: 401).

Classen (2005: 277) afirma que os visitantes em um museu, por exemplo, desejam tocar os objetos para "verificar sua natureza e experienciá-los intimamente". Isso porque o toque aproxima o sujeito do objeto, ao contrário da visão que implica sempre certa distância para que o observador possa ver o observado. O imbricamento de "quem toca" e do "que é tocado" aniquila "não apenas o espaço, mas também o tempo" (op.cit.: 277).

Assim como os visitantes de museus observados por Classen (2005), os moradores do entorno de sítios arqueológicos também desejam examinar os objetos, não apenas visualmente, mas, sobretudo, por meio da experiência tátil. Esse desejo, no entanto, revela mais do que uma mera curiosidade pelo objeto; o toque é um elemento significativo no processo de exploração e (re) conhecimento do mundo.

\section{As mãos que seguram os cacos}

As metáforas sensoriais elaboradas por membros das comunidades com as quais tenho convivido na Amazônia nos dão a medida da importância de mapear as relações sensíveis que eles estabelecem com suas paisagens. Imagens como "o poço tem sentimento", "os restos mortais da igreja", "o cabelo do mar", "a água morta" ou "escutar a terra" e "mexer

\footnotetext{
${ }^{5}$ A tradução é minha. Todos os demais trechos em língua inglesa serão, igualmente, traduzidos.
} 
no olho do poço para brotar água”, entre outras, demonstram o reconhecimento do ãnima nas coisas $^{6}$ e a relação com o domínio dos sentidos.

É assim que D. Darlete, agricultora e moradora da Transamazônica ${ }^{7}$, descreve uma tigela de cerâmica (MORAES, 2010):

(....... achou panelinha assim... de barro mesmo... lá é de barro mesmo... porque hoje vão fazer... tem no torno é bem pulida... a gente vê que ela é feita no manual... porque tem lugar que a gente vê assim a marca dos dedos assim... onde passa assim oh... os fundim do dedo sabe... e a boca não é tão redonda... é meia torta... não é dado um acabamento igual feito mesmo... uma coisa feito assim... mesmo no grosso sabe?

A descrição da peça é acompanhada pelos dedos de D. Darlete que esquadrinham a cerâmica para reconhecer a sua forma, percorrer suas reentrâncias e assim compreender aquele fragmento naturalizado pelo olhar, mas "estranhado", "destacado" pelo toque. Esse ato se repete em inúmeras ocasiões. Outra agricultora, Maria de Jesus, diz “(...) caco de pote tão bonitinho, assim riscadinho" (MORAES, 2010), mostrando a decoração incisa com a ponta dos dedos.

Já Valtinho, professor em Primavera ${ }^{8}$, e colecionador de objetos variados e, principalmente, de machados polidos, descreve o sistema sensorial acionado por ele - visão e tato - para identificar um machado polido encontrado nas proximidades de um sítio arqueológico:

Tá, o primeiro detalhe que eu percebo forma, olha só, o outro rapaz falou, foi a água, a chuva, mas ali onde ele achou não tem nenhum rio, não foi no rio, e outro detalhe é que eu acho também é que tá muito amoladinho, entendeu, e outro detalhe que eu percebo também, é pelo formato assim e tem um pequeno sulco que talvez seja pra colocar pedaço de pau pra amarrar e fazer a armação o que tá bem claro, bem evidente ali, essa aqui também tem, só que ela é, ela tem também aqui ó (Valtinho, Primavera).

Além de vários desses exemplos, observei, ao longo dos anos, a prática do esfregamento dos fragmentos, principalmente os de cerâmica, mas também os líticos. Esse ato tátil ativa a imaginação - e a memória - sobre experiências contemporâneas e sobre histórias do passado, mas também aponta para o que Ingold (2008: 3) chama de "engajamento

\footnotetext{
${ }^{6}$ (para uma discussão sobre a 'alma das coisas' ver LIMA FILHO, SILVEIRA, 2005)

${ }^{7}$ Projeto de Educação Patrimonial, coordenado por M. Bezerra, e desenvolvido no âmbito do "Programa de Arqueologia Preventiva Rodovia BR-163 (trecho guarantã do norte ao entroncamento da BR-230) e Rodovia BR-230 (trecho Miritituba-Rurópolis) DNIT/UFPA”, coordenado por Denise P. Schaan.

${ }^{8}$ Projeto de Educação Patrimonial, coordenado por M. Bezerra, e desenvolvido no âmbito do "Projeto Primavera - Prospecção Arqueológica e Educação Patrimonial na Área de Implantação da Fábrica de Cimento da Votorantim - Município de Primavera/PA Votorantim/Archaeo”, coordenado por Suzana Hirooka.
} 
ativo e exploratório da pessoa inteira (...)” num dado ambiente, ou seja, não apenas os órgãos dos sentidos como domínios em si, mas imbricados em uma teia técnico-simbólica.

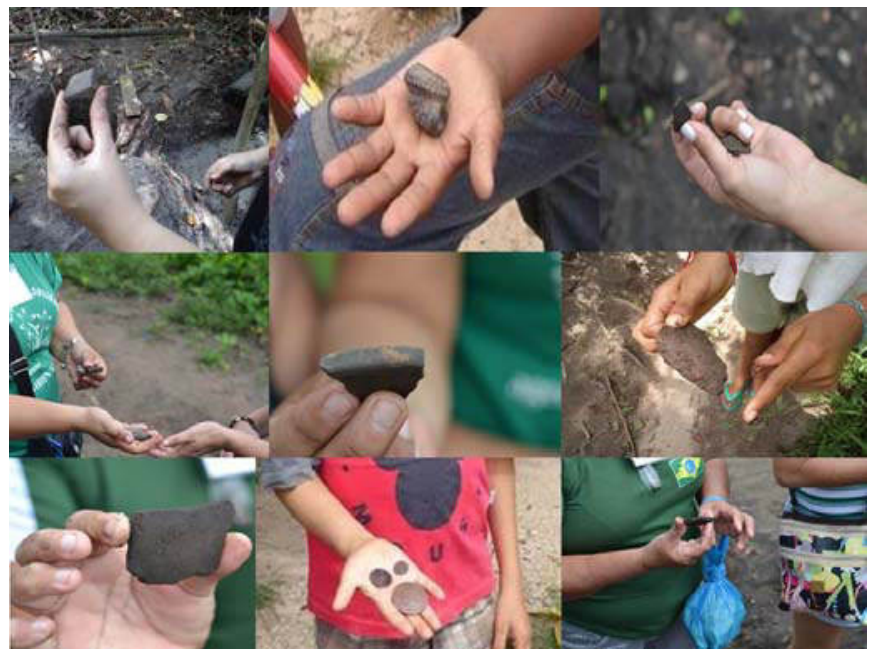

Figura 2: Esquadrinhando o Passado. Fotos: Marcia Bezerra, Monica Bezerra e Luis Ravagnani.

Ingold (2000) tem sido um dos principais críticos do campo da antropologia dos sentidos. Segundo ele, existe uma lacuna entre a "prática perceptual" e a "imaginação sensória" (op.cit.: 3) que tal proposição teórica não teria conseguido resolver a contento. Um de seus principais argumentos recai sobre o que ele considera um exagerado relativismo nas interpretações. Para ele, “(...) a antropologia dos sentidos (...) [deveria] se restituir aos mundos virtuais do sentido as praticidades de nossa maneira sensória de perceber o mundo." (op.cit.: 2) Embora reconheça essas divergências, entendo que seja proveitoso para a discussão lançar mão de elementos presentes em ambas as perspectivas.

Voltando à fruição tátil, considero importante pensar sobre essas práticas como percepções que ocorrem de "forma imediata" e, por isso, mais "grosseira", como afirma Kant (2006: 155), ao discorrer sobre a "faculdade do conhecer". A narrativa de S. Zuza, agricultor da cidade de Primavera, sugere essa percepção. Diz ele: “(...) acho que isso nasce na terra mesmo (...)", referindo-se a um objeto de cerâmica. A relação com a terra é crucial para essas comunidades. O principal meio de subsistência é a agricultura, seguido pela pesca, o que implica uma experiência cotidiana e tátil com a terra e o que nela for encontrado. $\mathrm{O}$ reconhecimento tátil das coisas faz parte das práticas agrícolas. As mãos e os dedos operam como instrumentos de exploração, de verificação, de construção de conhecimento. Assim, se por um lado os fragmentos de cerâmica ou de lítico são naturalizados em suas paisagens cotidianas, por outro, eles são "estranhados" no processo de esfregamento de suas superfícies. 


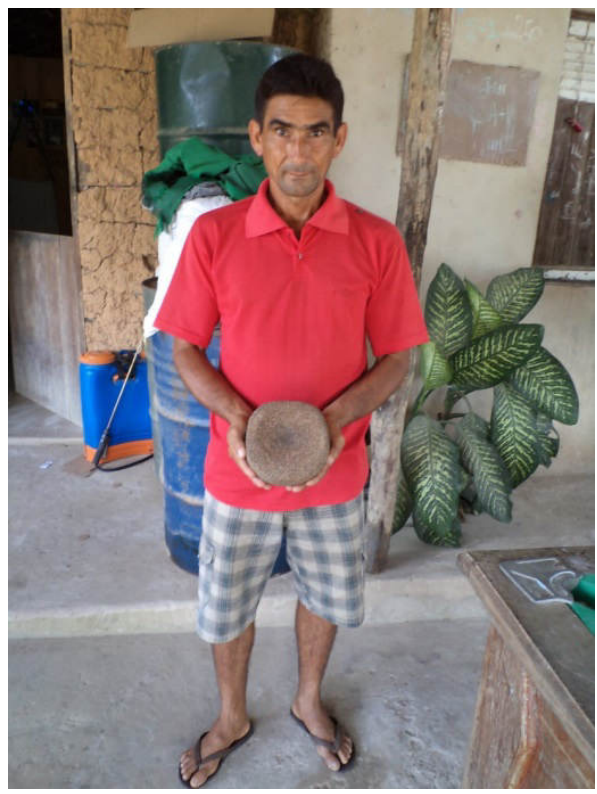

Figura 3: Sr. Zuza e o “jabuti”. Primavera, Pará. Foto: Marcia Bezerra.

As relações dessas comunidades com as coisas do passado são ativadas pela sensibilidade tátil, que é constituída por uma gama de conhecimentos empíricos sobre o ambiente, mas também pela "imaginação sensória" (INGOLD, 2008) sobre ele. Assim, tocar um objeto arqueológico significa incorporá-lo ao seu universo de conhecimento, a partir de uma lógica de raciocínio própria. Esses fragmentos - que para nós são partes de um todo representado por um objeto - constituem partes de outro todo: as paisagens vividas por essas pessoas. São também elementos com os quais têm uma relação metonímica, pois engendram uma teia de experiências e sentidos na qual estão imersos e imbricados.

Essa lógica também pode ser pensada no âmbito do trabalho do arqueólogo. No cotidiano da pesquisa arqueológica, nosso sistema sensorial é ativado a todo o momento como parte integrante do processo de identificação, análise e classificação de distintos materiais. MacGregor (2006: 155) afirma que "a classificação e o entendimento de alguns objetos podem ser mais dependentes de suas qualidades táteis do que visuais".

Todavia, quando se depara com o outro, a práxis da arqueologia, e da ciência em geral, vai de encontro a essa ideia. A interdição da percepção tátil do outro, do "nãoarqueólogo", em relação aos objetos, restringe a experiência sensorial, uma vez que apenas a visão é autorizada. Isso demonstra um descompasso da arqueologia contemporânea: por um lado os debates reforçam o discurso de descolonização das práticas; por outro, promovem a desvalorização e mesmo a supressão das formas sensoriais de fruição com o passado. Ou seja, a retórica da simetria dissimula as práticas de interdição. 
Os discursos sobre preservação e conservação do patrimônio também são domínios, por excelência, dessas idiossincrasias. Os especialistas - arqueólogos, museólogos, restauradores, conservadores - têm o benefício da fruição com os objetos, os que se encontram fora desse restrito grupo são orientados a não tocar nas coisas do passado. E, mais do que isso, têm sua percepção sensorial disciplinada pela retórica patrimonial e as suas epistemologias aniquiladas pelo discurso da ciência.

Canclini (2003: 160) ao discutir sobre as funções do patrimônio argumenta que esses bens, ao serem tomados, a priori, como prestigiosos e duradouros dons recebidos do passado, são considerados inquestionáveis e, por isso, passíveis apenas de atos que promovam a sua preservação, conservação e difusão. Para o autor, é essa perspectiva que faz do patrimônio “(...) o lugar onde melhor sobrevive hoje a ideologia dos setores oligárquicos, quer dizer, o tradicionalismo substancial" que impede que os vários grupos interessados no patrimônio encenem os seus distintos modos de fruição com o passado.

Chauí (1981), por sua vez, ao refletir sobre o papel da ciência, afirma que o seu distanciamento da sociedade e a natureza privada do conhecimento por ela produzido, instalam o que ela denomina "discurso competente", segundo o qual:

(...) não é qualquer um que pode dizer qualquer coisa a qualquer outro em qualquer ocasião e em qualquer lugar. Com esta regra, ele produz sua contraface: os incompetentes sociais (...) (CHAUÍ, 1981: 2).

O discurso da competência recrudesce a autoridade do pesquisador e, no caso da Arqueologia, contribui para o arruinamento de outras lógicas de conhecimento e para a instrumentalização do patrimônio.

Londoño (2003: 4) ao tratar da exclusão de outros sentidos da materialidade, no caso da prática campesina da "guaquería", afirma que os grupos envolvidos nessas práticas têm suas formas particulares de lidar com a materialidade pré-hispânica, com base em outras lógicas e outros pesos. Para o autor, o "puritanismo jurídico" aplicado ao patrimônio impossibilita a democratização dos discursos sobre o passado.

É nessa mesma perspectiva que Smith (2007: 2) lança mão da noção de "tecnologia de governo", desenvolvida por Rose e Miller (1992: 175) em referência ao conjunto de programas, técnicas, aparatos, documentos e procedimentos pelos quais "as autoridades

\footnotetext{
${ }^{9}$ Prática de saque aos sítios arqueológicos. Nas palavras de Londoño (2003:6) "La guaquería, en efecto, es uma forma cultural, socialmente estabelecida, por médio de la cual ciertos indivíduos se representan a sí mismos la existência de lo que para los arqueólogos y los juristas constituye el registro arqueológico." O autor não pretende dizer que o Estado não deva salvaguardar o patrimônio arqueológico.
} 
procuram incorporar e efetuar as ambições governamentais." Smith propõe pensar o patrimônio arqueológico como "tecnologia de governo", um aparato constituído pela autoridade disciplinar e pela ideia de expertise.

O não reconhecimento das práticas de fruição com o passado, e suas coisas, legitima a posição de privilégio da Arqueologia no mundo ocidental e reforça a sua condição de "tecnologia de governo". De forma circular, esses dois fatores contribuem para a depreciação das perspectivas nativas sobre a interpretação do registro arqueológico, a gestão e a conservação $^{10}$ (BEZERRA, MACHADO, 2011) do repertório material que compõe os sítios arqueológicos.

\section{Considerações finais}

Os singulares exemplos de fruição com a cultura material na Amazônia contribuem para os estudos sobre as percepções que as comunidades moradoras do entorno de sítios arqueológicos têm do que se convencionou chamar "patrimônio arqueológico". Pensar nessas relações a partir de sua dimensão sensorial revela as complexas nuances dessas elaborações e ainda aponta um caminho fértil para se rever as ações de preservação e refletir sobre as práticas disciplinares, considerando as dissonâncias sensíveis do discurso da Arqueologia contemporânea.

Com essas reflexões iniciais sobre as relações sensoriais entre as pessoas de hoje e as coisas do passado, pretendi mostrar que o entendimento das formas de apropriação do que denominamos "patrimônio arqueológico" não pode prescindir do mapeamento dos modos perceptuais de fruição. Além disso, ressaltei que a opção pela produção do campo da Antropologia dos Sentidos pode enriquecer os estudos sobre o reconhecimento de sistemas sensoriais distintos em contextos arqueológicos. Em seguida, indiquei alguns exemplos nos quais moradores de pequenas localidades na Amazônia narram suas experiências táteis com os objetos arqueológicos. Por fim, concluí que ambos os discursos da ciência e do patrimônio disciplinam, interditam e ordenam as percepções sensoriais do outro, instaurando paisagens de poder (Lima Filho; Silveira, 2005) que afetam a legitimidade dos sentidos contemporâneos das coisas do passado na Amazônia.

\footnotetext{
${ }^{10}$ Para discussão sobre as práticas descolonizantes na preservação e conservação de bens culturais ver Sully (2009).
} 


\section{Agradecimentos}

Aos moradores de Joanes, Rio dos Cacos e Água Azul pela acolhida e por autorizarem o uso de suas narrativas e imagens.

Aos organizadores da I Semana de Arqueologia da Unicamp.

\section{Referências Bibliográficas}

BARRETO, Cristiana N. G. Meios místicos de reprodução social: arte e estilo na cerâmica funerária da Amazônia Antiga. 2008. Tese. Programa de Pós-Graduação em Arqueologia, Universidade de São Paulo, São Paulo, 2008.

BELL, Joshua A.; GEISMAR, Haidy Materialising Oceania: new ethnographies of things in Melanesia and Polynesia. Australian Journal of Anthropology, vol.20, n.3, p. 3-27, 2009.

BEZERRA, Marcia. Signifying Heritage in Amazon: a public archaeology project at Vila de Joanes, Marajó Island, Brazil. Chungara, vol. 44, n. 3, p. 363-373, 2012.

BEZERRA, Marcia; MACHADO, Almires M. They Also Get Angry: indigenous things and conservation practices in museum collections. Apresentado durante o Indigenous People and Museums Unraveling the Tensions Inter-Congress of the World Archaeological Congress, Indianapolis, 2011. (não publicado)

CABRAL, Mariana P. E se todos fossem arqueólogos? Pensando o encontro da Arqueologia $e$ da Simetria na prática. Apresentado no XV Congresso da Sociedade de Arqueologia Brasileira, Florianópolis, 2011. (gentilmente cedido pela autora)

CANCLINI, Néstor G. Culturas Híbridas. São Paulo, EDUSP, 2003.

CASTAÑEDA, Quetzil. E. The 'Ethnographic Turn' in archaeology. Research positioning and reflexivity in ethnographic archaeologies. In: CASTAÑEDA, Quetzil E.; MATTHEWS, Christopher N. (eds.) Ethnographic Archaeologies: Reflections on Stakeholders and Archaeological Practices. Altamira Press, p. 25-61, 2008.

CHAUÍ, Marilena. Cultura e democracia: o discurso competente e outras falas. São Paulo, Moderna, 1981.

CLASSEN, Constance. Foundations for an Anthropology of the Senses. International Social Science Journal, vol. 49, n. 153, p. 401-412, 1997.

CLASSEN, Constance. (ed.) The Power of Touch. Oxford, New York, Berg, 2005.

COLWEL-CHANTHAPHONH, Chip; FERGUSON, T. J. (eds.) Collaboration Archaeological Practice: engaging descendants communities. Altamira Press, 2008.

DAY, Jo (ed.) Making Senses of the Past: Toward a Sensory Archaeology. Southern Illinois Press, 2013. 
EBBIT, Alicia. Heritage Education in Belize: crossing disciplines and incorporating diverse voices. In: PEREIRA, Edithe; GUAPINDAIA, Vera (orgs.) Arqueologia Amazônica. vol. 2, Belém, Museu Paraense Emílio Goeldi, p. 1053-1072, 2010.

EDWARDS, Elizabeth, GOSDEN, Chris; PHILLIPS, Ruth B. (eds.) Sensible Objects: colonialism, museums and material culture. New York, Berg, 2006.

FAHLANDER, Fredrik; KJELLSTRÖM, Anna. Making Senses of Things: Archaeologies of Sensory Perception. Stockholm University, 2010.

FERREIRA, Lúcio M.; FERREIRA, Maria Letícia M.; ROTMAN, Mónica B. (orgs.) Patrimônio Cultural no Brasil e na Argentina: Estudos de Caso. São Paulo, Annablume, 2011.

FUNARI, Pedro Paulo; BEZERRA, Marcia Public Archaeology in Latin America. In: SKEATES, Robin; MCDAVID, Carol; CARMAN, John (eds.) The Oxford Handbook of Public Archaeology. Oxford University Press, p.100-115, 2012.

GNECCO, Cristóbal; AYALA, Patricia (eds.) Pueblos Indígenas y Arqueologia en America Latina. Ediciones Uniandes, 2010.

GOMES, Denise M. C. O perspectivismo ameríndio e a ideia de uma estética americana. Boletim do Museu Paraense Emílio Goeldi. Ciências Humanas, Belém, vol. 7, n. 1, p.133-159, 2012.

HAMILAKIS, Yannis; PLUCIENNIK, Mark; TARLOW, Sarah (eds.) Thinking through the Body: Archaeologies of Corporeality. Kluwer Academic, Plenum Publishers, 2002.

HERRERA, Alexander; LANE, Kevin. Qué Hacen Aquí Esos Pishtaku?: Sueños, Ofrendas y La Construcción del Pasado. Antípoda, n. 2, p.157-177, 2006.

HODDER, Ian. Entangled: An Archaeology of the Relationships Between Human and Things. Wiley-Blackwell, 2012.

HOWES, David. (ed.) The Varieties of Sensual Experience: A Sourcebook in the Anthropology of the Senses. Toronto, University of Toronto Press, 1991.

HURCOMBE, Linda. A Sense of Materials and Sensory Perception in Concepts of Materiality. World Archaeology, vol. 39, n.4, p. 532-545, 2007.

INGOLD, Tim. Perceptions of the Environment: Essays in Livelihood, Dwelling and Skill. Routledge, 2000.

INGOLD, Tim. Pare, olhe, escute! - um prefácio. Tradução de ROMÃO, Ligia M.V.; BALIEIRO, Marcos; VALENTINI, Luisa FRANK, Eliseu; FIORE, Ana Letícia de; HARAYAMA, Rui Ponto Urbe: Revista do Núcleo de Antropologia Urbana da USP. Ano 2, versão 3.0, 3p., julho de 2008.

KANT, Immanuel. Antropologia de um Ponto de Vista Pragmático. São Paulo, Iluminuras, 2006. 
LIMA FILHO, Manuel F.; SILVEIRA, Flávio L. Por uma Antropologia do Objeto Documental. Horizontes Antropológicos, ano 11, n. 23, p.37-50, 2005.

LONDOÑO, Wilhem. Discurso jurídico versus discurso cultural. El conflicto social sobre los significados de la cultura material prehispánica. Boletín del Museo del Oro, n. 51, 1-26, 2003. Disponível em http://www.banrep.gov.co/museo/esp/boletin. Acesso em 18 de dezembro de 2012.

MACDAVID, Carol. Archaeologies that Hurt: Descendants that Matter: A pragmatic approach to collaboration in the public interpretation of African-American archaeology. World Archaeology, vol. 34, n. 2, p. 303-314, 2002.

MACGREGOR, Gavin Making Sense of the Past in the Present: a sensory analysis of carved stone balls. World Archaeology, vol. 31, n.2, p. 258-271, 1999.

MACGREGOR, Gavin Making. Monuments Out of Mountains: The Role of Colour and Texture in the Constitution of Meaning and Identity at Recumbent Stone Circles. In: JONES, Andrew; MACGREGOR, Gavin (eds.) Colouring the Past: The Significance of Colour in Archaeological Research. p. 141-158, 2002.

MACHADO, Juliana S. Lugares de Gente: mulheres, plantas e redes de troca no Delta Amazônico. 2012. Tese. Programa de Pós-Graduação em Antropologia Social, Museu Nacional/Universidade Federal do Rio de Janeiro, Rio de Janeiro, 2012.

MARSHALL, Yvonne. What is Community Archaeology? World Archaeology, vol. 34, n. 2, p. 211-219, 2002.

MIRE, Sada. Preserving Knowledge, not Objects: a Somali perspective for heritage management and archaeological research. African Archaeological Review, vol. 24, p. 49-71, 2007.

MORAES, Irislane P. de Centralidades do Patrimônio na Amazônia: considerando as percepções de mulheres agricultoras em um Projeto de Educação Patrimonial na região de Itaituba-PA. 2010. Monografia de Especialização. Universidade Federal do Pará, Belém, 2010.

MORAES, Irislane P. de Povos do Aproaga: patrimônio, arqueologia e territorialidade quilombola em São Domingos do Capim (PA). 2012. Dissertação. Programa de PósGraduação em Antropologia, Universidade Federal do Pará, Belém, 2012.

NAJJAR, Rosana Arqueólogos e Comunidade: parceiros ou rivais? Revista de Arqueologia Americana, n. 21, p. 173-190, 2001.

OKAMURA, Katsuyuki; MATSUDA, Akira (eds.) New Perspectives in Global Public Archaeology. Springer, 2011.

OUZMAN, Sven. Seeing is Deceiving: rock art and the non-visual. World Archaeology: vol. 33, n.2, p. 237-256, 2001. 
PYBURN, K. Anne. Practicing Archaeology - As If It Really Matters. Public Archaeology, vol. 8, n. 2-3, p. 161-175, 2009.

PYE, Elizabeth. Introduction: The Power of Touch. In: PYE, E. (ed.) The Power of Touch: handling objects in museums and heritage. Walnut Creek, CA, Left Coast Press, p.13-30, 2007.

RAVAGNANI, Luis R. O Patrimônio Arqueológico na Percepção de Professores e Alunos da Vila de Joanes, Ilha do Marajó. 2011. Monografia de Graduação. Faculdade de Ciências Sociais, Universidade Federal do Pará, 2011.

ROSE, Nicholas; MILLER, Peter. Political Power Beyond the State: problematics of government. British Journal of Sociology, vol.43, p. 173-205, 1992.

SABLOFF, Jeremy. Archaeology Matters: action archaeology in the modern world. Left Coast Press, 2008.

SANTOS GRANERO, Fernando. The Occult Life Of Things: native amazonian theories of materialization and personhood. Tucson, University of Arizona Press, 2009.

SCHAAN, Denise P. The Camutins Chiefdom: rise and development of complex societies on Marajó Island, Brazilian Amazon. 2004. Tese. PhD in Anthropology, University of Pittsburgh, Pittsburgh, 2004.

SILVA, Fabíola A. Mito e Arqueologia: A Interpretação dos Asurini do Xingu sobre os Vestígios Arqueológicos encontrados no Parque Indígena Kuatinemu - Pará. Horizontes Antropológicos, vol.17, p.175-187, 2002.

SKEATES, Robin. An Archaeology of the Senses: Prehistoric Malta. Oxford University Press, 2010.

SMITH, Laurajane. Empty Gestures? Heritage and the Politics of Recognition. In: SILVERMAN, Helaine; RUGGLES, D. Fairchild. (eds.) Cultural Heritage and Human Rights: Springer, New York, 159-171, 2007.

STANCHI, Roberto A. Proteção ao Patrimônio Arqueológico no Brasil e no Peru: comparando experiências. Resumos. XI Congresso da Sociedade de Arqueologia Brasileira, 2001, Rio de Janeiro, p. 158. (não publicado)

STOLLER, Paul. The Taste of Ethnographic Things: The Senses in Anthropology. Philadelphia, University of Pennsylvania Press, 1989.

SULLY, Dean (ed.) Decolonising Conservation: caring for Maori meeting houses outside New Zealand, Walnut Creek, Left Coast Press, 2009.

THOMAS, Nicholas. Entagled Objects: Exchange, Material Culture and Colonialism in the Pacific. Cambridge, MA, Harvard University Press, 1991.

VELTHEM, Lúcia H. van. O belo é a fera: a estética da produção e da predação entre os Wayana. Lisboa, Assírio \& Alvim, 2003. 
VIVEIROS DE CASTRO, Eduardo. Os pronomes cosmológicos e o perspectivismo ameríndio. Mana, vol. 2, n. 2, p. 115-144, 1996.

ZARANKIN, Andrés. "Once upon a time..." Historias no contadas sobre arqueólogos en Antártida. VI Reunión de Teoría Arqueologica de América del Sur. Goiânia, 2012. (gentilmente cedido pelo autor). 